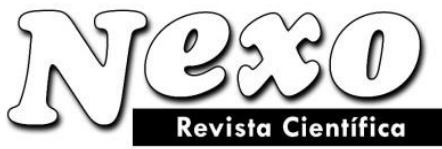

Vol. 34, No. 02, pp. 942-949/Junio 2021

\title{
Risk reduction at oil and gas industry using methods of synthesis of flame retardant coatings
}

\section{Reducción del riesgo en la industria petrolera y de gas utilizando métodos de síntesis de recubrimiento retardantes de llama}

\author{
Svyatoslav Stolyarov ${ }^{*}$, Tatiana Vlasova, Aslan Akhriev, Grigory Shidlovsky, Farid Dali, Dmitry Tishkin \\ Saint Petersburg University of State Fire Service of Emercom of Russia, Saint Petersburg, Russian \\ Federation.
}

*Corresponding author: stolyarov.svyatoslav@list.ru

(recibido/received: 03-febrero-2021; aceptado/accepted: 15-abril-2021)

\begin{abstract}
This article studies the influence of zeolites with microencapsulated water on flame retardant efficiency of intumescent compositions with epoxy resins under conditions of hydrocarbon jet fire. The flame retardant efficiency has been simulated and estimated using regression analysis. The synthesis of ablation/desorption flame retardant coatings is described.
\end{abstract}

Keywords: Flame retardant efficiency; Flame retardant intumescent composition; Microencapsulated zeolites; Simulation; Regression analysis.

\section{RESUMEN}

Este artículo estudia la influencia de las zeolitas con agua microencapsulada sobre la eficacia retardante de llama de composiciones intumescentes con resinas epoxi en condiciones de fuego de chorro de hidrocarburos. La eficiencia del retardante de llama se ha simulado y estimado mediante análisis de regresión. Se describe la síntesis de recubrimientos ignífugos de ablación / desorción.

Palabras claves: Eficacia retardante de llama; Composición intumescente ignífuga; Zeolitas microencapsuladas; Simulación; Análisis de regresión.

\section{INTRODUCTION}

Fire hazard of oil and gas industry (hereinafter, OGI), is mainly related with amount and type of involved fire load. Hydrocarbon fires emerging at OGI entities lead to sharp temperature increase and impact on supporting structures. In order to prevent destruction, the structures are treated with fire retardant intumescent compositions (hereinafter, FRIC), which under the action of high temperatures generate protective heat-insulating layer. The efficiency of such compositions is determined by their specifications. A drawback of the flame retardant compositions used at OGI entities is insufficient flame retardant efficiency in the case of hydrocarbon jet fire (Choiy, 2016). 
They can be improved using the following methods: modification of filming agents, addition of fire retardants and inhibitors, chemical and physical modification, microencapsulation, nanomodification.

The main drawbacks of these methods are that they can be applied only during production, high toxicity of combustion products, changes of chemical composition with deterioration of operation performances in the case of high amount of modifiers in FRIC.

Therefore, it would be relevant to consider the methods of physical modification, nanomodification, and microencapsulation, which have certain limitations. It is necessary to develop new and to enhance the existing methods of improvement of FRIC performances for the cases of hydrocarbon fire.

One of the existing methods of improvement of FRIC performances is deposition of functional components into the formulation of flame retardant composition. Porous fillers with microencapsulated fire extinguishing agents (FEA) have been proved to be successful, significantly improving FRIC flame retardant properties at low content.

\section{METHODS}

This study was performed with the flame retardant composition: Thermobarrier 2. Modifying agents were natural zeolites with the particle sizes of $40 \mu \mathrm{m}$ with microencapsulated water adsorbed by active diffusion.

The considered components were obtained by mixing of modified curing agent and thermoplastic filming agent. Prior to this, microencapsulated zeolites were added to the curing agent in the content of $1-5 \mathrm{wt} \%$. After mixing of the curing agent with filming agent the obtained mixture was agitated mechanically to homogeneous state.

The flame retardant composition was applied on the basis of the specifications for main composition. Steel plates, Grade St 3, with the sizes of $100 \times 50 \times 6 \mathrm{~mm}$ were used as substrates.

The flame retardant efficiency of the considered pieces was analyzed using a laboratory unit simulating temperature and erosion impact of hydrocarbon flame (Choiy, 2016). The pieces were placed into the experimental chamber, the temperature of the back plate side was measured by two thermocouples, the fuel gas flow rate of propane-butane burner was $50 \ldots 60 \mathrm{~g} / \mathrm{h}$ at the pressure of $0.1 \mathrm{MPa}$, the gas flow temperature was measured by thermocouples. The ultimate state was determined as reaching the temperature of plate back side equaling to $500^{\circ} \mathrm{C}$ according to State Standard GOST R 53295-2009.

The thickness of flame retardant layer was measured by a MT-201-00 magnetic thickness meter (State Standard GOST R 51694, ISO 2808). The thickness of expanded layer was determined using a caliper.

In order to determine the influence of filler on performances and flame retardant efficiency of FRIC, it seemed reasonable to develop mathematical model of the considered system.

In order to solve the regression problem, the occurrence time of ultimate state of the protected surface with FRIC was simulated, the simulations were performed using REGRAN software (Tarantsev et al., 2016). In order to estimate the influence of input factors (IF) $-X_{1} \div X_{7}$ (Table 1) - on the output parameter (OP), occurrence of ultimate state $(Y)$ at various combinations of IF (Figure 1) was determined. The experiments were repeated five times to obtain reliable estimation. 


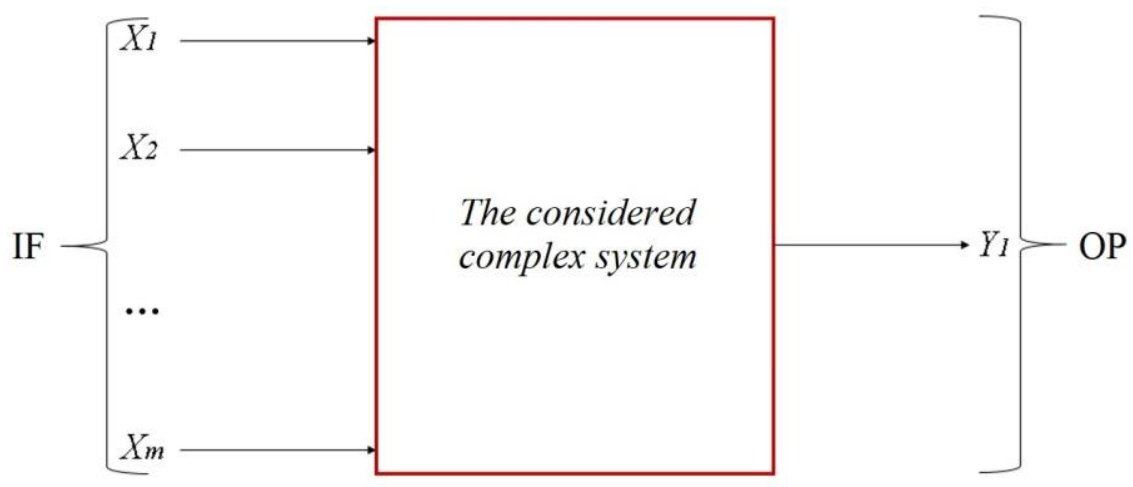

Figure 1. Model of the system

The OP is determined by Eq. (1) (Nalimov and Chernova, 1965):

$$
y=f\left(X_{1}, \ldots, X_{7}\right)
$$

A series of experimental studies were caried out, which confirmed possibility to use zeolites with microencapsulated water as a FRIC modifying agent, which provided improvement of performances of the considered flame retardant compositions (Ivakhnyuk et al., 2019). However, deposition of numerous types of FEA into FRIC is restricted, which is related with incompatibility of these components with some types of polymer bases (Ivakhnyuk and Stolyarov, 2018). The method of active diffusion makes it possible to store and to deposit various substances in adsorbents without sorbent loss before changes of external environment (temperature, pressure, chemical impact), which makes this method promising for the purpose of improvement of FRIC performances applied under the conditions of high temperature impact of hydrocarbon flame (Keltsev, 1984).

Thermal and adhesion properties of FRIC modified by microencapsulated zeolites were estimated in (Ivakhnyuk et al., 2019). It was detected that addition of zeolites with microencapsulated water (3 wt \%) promoted improvement of FRIC performances, namely:

- the strength of FRIC adhesion to the protected surface increased;

- cumulative thermal effect upon thermal decomposition increased,

- coke residue increased;

- material flammability decreased;

- the rate of weight loss of substance decreased.

In order to estimate the changes of flame retardant efficiency under various combinations of the factors $\left(X_{1} \div X_{7}\right)$, it was proposed to carry out regression analysis.

Table 1. Variables for regression analysis

\begin{tabular}{|c|c|c|}
\hline Notation & Description & Units of measurement \\
\hline$X_{1}$ & Concentration of zeolites in curing agent, $\varphi$ & vol \% \\
\hline$X_{2}$ & Adhesion strength & $\mathrm{kgf} / \mathrm{cm}^{2}$ \\
\hline$X_{3}$ & Bloating coefficient $\left(K_{\mathrm{bl}}\right)$ & $h_{\mathrm{b} 1} / h_{0}$ \\
\hline$X_{4}$ & Flammability of OI & $\%$ \\
\hline
\end{tabular}




\begin{tabular}{clc}
\hline Notation & \multicolumn{1}{c}{ Description } & Units of measurement \\
\hline$X_{5}$ & Specific heat of exothermal reactions in the temperature range & $\mathrm{J} / \mathrm{g}$ \\
$X_{6}$ & Heat of exothermal peak 2 & $\mathrm{J} / \mathrm{g}$ \\
$X_{7}$ & Heat of exothermal peak 3 & $\mathrm{J} / \mathrm{g}$ \\
$Y$ & Occurrence time of ultimate state of protected surface. & $\mathrm{min}$ \\
\hline
\end{tabular}

The regression analysis of achievement of ultimate state of protected surface with FRIC under the conditions of thermal and erosion impact of hydrocarbon jet fire was comprised of:

1) Obtaining quasilinear regression equation (Tarantsev et al., 2016) of achievement of ultimate state of protected surface with FRIC as a function of performances of flame retardant composition.

2) Selection of conditional factors by brute force.

3) Calculation of regression coefficient by the least square method.

4) Estimation of adequacy of regression analysis using Fisher's test and calculation of maximum mismatch between experimental and predicted value of OP.

Using REGRAN software, the regression coefficients were calculated and the conditional factors were selected. OP as a function of IF was described by a set of adequate equations, thus, the regression models were obtained using the multimodality principle (Ivanov et al., 2017), which provided valid prediction of OP $\left(Y_{1}\right)$ and estimation of significance of the IF $\left(X_{1} \div X_{7}\right)$.

The flame retardant efficiency as a function of FRIC performances was described by the quasilinear regression equation (Tarantsev et al., 2016).

$$
y=\sum_{i=1}^{M} b_{i} h_{i}
$$

where $b_{i}$ was the $i$-th predicted regression coefficient; $h_{i}$ was the $i$-th conditional factor determined as a function of IF $X_{1} \div X_{7} ; K$ was the number of regression coefficients or conditional factors $(K<N)$.

The values of $\left\{h_{i}\right\}$ were determined by brute force, $\left\{b_{i}\right\}$ - using the least square method (Kritenko et al., 1995) with accounting for Eq. (3):

$$
D_{j}=\left(N-K_{j}\right)^{-1} \cdot \sum_{j=1}^{N}\left(a_{j i}^{E}-a_{j i}^{P r}\right)^{2} \rightarrow \min ,
$$

where $a_{j i}^{E}, y_{j i}^{P r}$ were the $j$-th OP obtained by Eq. (2) during the $i$-the test, respectively, for the $i$-th combination of IF.

The adequacy of Eq. (2) (Bolshev and Smirnov, 1983) was estimated using Fisher's $F$-test (Wentzel, 1998), with the accuracy sufficient for engineering calculations (Eq. (4)) and maximum mismatch $\Delta$ between experimental and predicted values of OP (Eq. (5)):

$$
F_{j}=\frac{D_{j o}}{D j},
$$

where $D_{j o}$ was the dispersion of tests.

$$
\Delta=\max _{i=1}^{N}\left|a_{j i}^{E}-a_{j i}^{P r}\right| .
$$


The regression coefficients $\left\{b_{i}\right\}$ were predicted by means of REGRAN software, and the conditional factors $\left(h_{1}, \ldots, h_{k}\right)$ were selected. OP as a function of IF was described by a set of adequate equations, thus, the regression models were plotted using multimodality principle (Ivanov et al., 2017), which provided valid prediction of the OP $\left(Y_{l}\right)$ and estimation of significance of the $\operatorname{IF}\left(X_{1} \div X_{7}\right)$.

\section{RESULTS AND DISCUSSION}

The experimental results demonstrate that addition of zeolites to FRIC improves the considered properties (Figure 2). Under the impact of hydrocarbon jet fire, the reference sample reached the ultimate temperature of $500^{\circ} \mathrm{C}$ at the 65 th minute, while the samples modified by microencapsulated zeolites could maintain this test mode more efficiently in average by $80 \%$ for the samples with zeolite content in curing agent equaling to $1-5 \mathrm{wt} \%$.

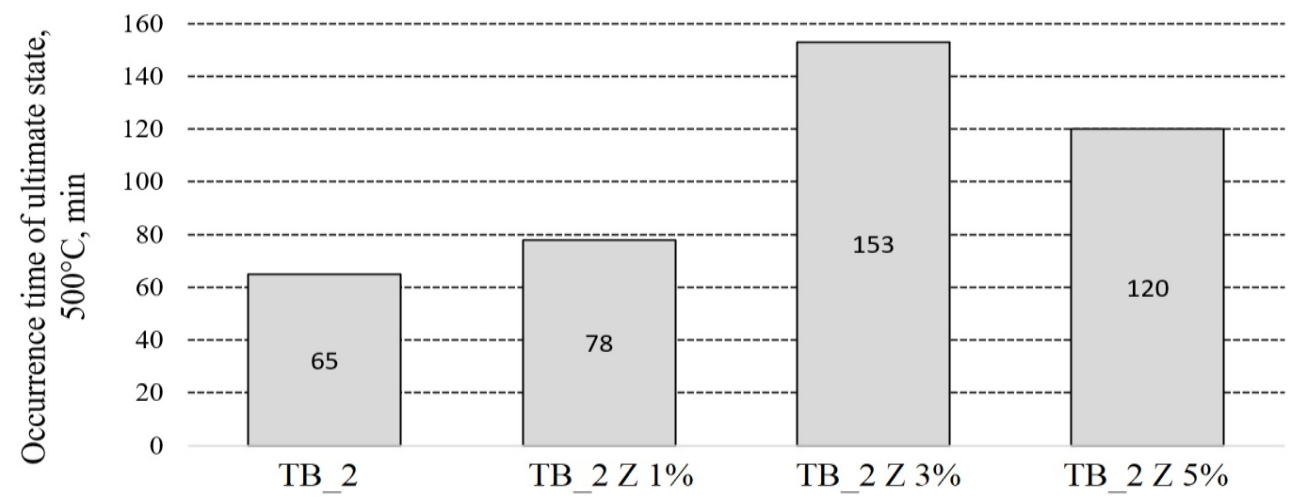

Figure 2. Flame retardant efficiency of the considered samples in the case of hydrocarbon jet fire: (TB_2 -

Thermobarrier 2; TB_2 Z 1\% - Thermobarrier 2 containing $1 \mathrm{wt} \%$ of zeolites with microencapsulated water)

On the basis of firing tests, the bloating coefficient $\left(K_{b l}\right)$ was determined by the equation:

$$
\mathrm{K}_{b l}=h_{b l} / h_{0}
$$

where $h_{\mathrm{bl}}$ was the thickness of bloated layer, $h_{0}$ was the initial thickness of coating.

The experimental results have demonstrated that addition of zeolites decreased the bloating coefficient in average by $12.7 \%$ (Table 2 ).

Table 2. Bloating coefficient as a function of zeolite content

\begin{tabular}{ccccccc}
\hline & \multicolumn{7}{c}{ Zeolite content in FRIC, wt \% } \\
\cline { 3 - 8 } & 0 & 1 & 2 & 3 & 4 & 5 \\
\cline { 4 - 8 } & 2.00 & 1.70 & 1.75 & 1.82 & 1.80 & 1.74 \\
\hline
\end{tabular}

The results of regression analysis of ultimate state occurrence of the considered samples are summarized in Table 3.

Table 3. Regression models

\begin{tabular}{ccc}
\hline Regression equation $(7)$ & $F$ \\
\hline$Y_{1}=17.29 \cdot X_{1} \cdot X_{3}^{2}-2.416 \cdot X_{1}^{2} \cdot X_{3}^{2}-38.03 X_{3}+34.93 X_{3}^{2}$ & 21.0 & 6.96 \\
$Y_{1}=-8.814-11.09 \cdot X_{6}^{2}+11.84 \cdot X_{3}^{2} \cdot X_{6}$ & 72.6 & 4.91 \\
$Y_{1}=9.751 \cdot X_{1}^{2} \cdot X_{3} \cdot X_{6}^{2}-1.081 \cdot X_{1}^{2} \cdot X_{3} \cdot X_{6}+13.17 \cdot X_{1} \cdot X_{3}^{2}+16.11 \cdot X_{3}^{2}$ & 777.0 & 1.32 \\
$Y_{1}=-842.7 \cdot X_{1}^{2} \cdot X_{6}^{2}-11.27 \cdot X_{2} \cdot X_{6}+47.77 \cdot X_{3} \cdot X_{6}$ & 210.0 & 3.31 \\
\hline
\end{tabular}


The regression analysis has revealed the main influencing factors (in descending order of their influence on $\mathrm{OP})$ :

- $X_{I}$ (zeolite concentration in curing agent);

- $X_{3}$ (bloating coefficient);

- $X_{6}(Q$ of exothermal peak 2$)$.

The IF $X_{2}, X_{4}, X_{5}$, and $X_{7}$ were not used due to high mutual correlation.

The use of the considered mathematical apparatus allows developing recommendations for improvement of performances of flame retardant coatings under conditions of hydrocarbon jet fire.

The obtained results have allowed developing the method of improvement of flame retardant efficiency of flame retardant coatings, which is used during technology audit of OGI companies.

The method of improvement of performances of flame retardant coatings is comprised of the following stages:

1) Analysis of technological state of comprehensive technology audit of an OGI company.

2) Determination of conformity of flame retardant efficiency of the applied flame retardant coatings with operating environment at OGI companies.

3) Determination of opportunity to synthesize modifying component with FRIC filming agent.

4) Analysis of FRIC performances (adhesion strength $\left(\mathrm{W}_{2}\right)$, bloating coefficient $\left(K_{b l}\right)$, heat of exothermal peak $1\left(Q_{d s c 1}\right)$, heat of exothermal peak $2\left(Q_{d s c 2}\right)$, heat of exothermal peak $3\left(Q_{d s c 3}\right)$, oxygen index (OI));

5) Prediction of operation performances (according to Eq. (7):

$$
T_{\text {f.p. }}=f\left(Y_{\text {fr.eff.. }}\right)
$$

6) According to the predicted performance of modified FRIC, the following condition should be valid:

$$
Y_{\text {fr.eff.. }}>Y_{\text {fr.eff.. FS }}
$$

7) Preparation of modified additive in accordance with synthesis features of flame retardant coatings.

8) Implementation of synthesis technology of ablation/desorption flame retardant coatings in order to provide the required limit of fire resistance of constituent metal structures at OGI entities for the conditions of hydrocarbon jet fire.

Implementation of synthesis of ablation/desorption flame retardant coatings allows to provide the required limit of fire resistance of metal structures. The main trend of application of functional components in FRIC formulation is nonreagent modification and changes of performances of basic flame retardant compositions. 
The procedure of synthesis of ablation/desorption flame retardant coatings for equipment of OGI entities can be used to improve fire safety and as a constituent of general system of fire protection. Using the synthesis of functional components of FRIC formulation, it is possible to increase the occurrence time of ultimate state of metal structures in the case of possible emergencies related with heat and erosion impact under the conditions of hydrocarbon jet fire on a structure of OGI equipment.

\section{CONCLUSION}

Deposition of microencapsulated zeolites into FRIC composition improves flame retardant efficiency in average by $80 \%$.

The regression analysis has detected that the factors of improvement of flame retardant efficiency upon deposition of microencapsulated zeolites into FRIC composition are as follows:

- bloating coefficient;

- thermal effect of exothermal peak at the range of $600-700^{\circ} \mathrm{C}$;

Application of the correlation and regression analysis of flame retardant efficiency of modified flame retardant coatings allows developing recommendations for improvement of performances of flame retardant coatings under the conditions of hydrocarbon jet fire.

The experimental results of improvement of performances of flame retardant coatings modified by zeolites demonstrate the possibility of applying the synthesis of FRIC with microencapsulated zeolites during hydrocarbon fires at economic entities, namely in OGI.

\section{REFERENCES}

Bolshev, L. N. and Smirnov, N. V. (1983). Tables of mathematical statistics: textbook. Manual for universities. Moscow, Russia: Nauka.

Choiy, A. A. (2016). Influence of the conditions of flare hydrocarbon combustion on fire-retardant coatings of steel structures. New Science: Theoretical and Practical View, 4-2 (75), 211-213.

Ivakhnyuk, G. K. and Stolyarov, S. O. (2018). Physicochemical modeling of formulations of highly effective fire retardant coatings. Problems of Risk Management in the Technosphere, 4, 34-40.

Ivakhnyuk, G. K., Stolyarov, S. O. and Dementyev, F. A. (2019). Study of the operational characteristics of modified flame retardant coatings based on epoxy resins. Problems of risk management in the technosphere, 4, 141-151.

Ivanov, A. V., Miftakhutdinova, A. A., Nefediev, S. A., Simonova, M. A. and Maslakov, M. D. (2017). Stabilization conditions for nanostructures for the safe transportation of flammable liquids. Fire and Explosion Safety, 26(9), 35-43.

Keltsev, N. V. (1984). Fundamentals of adsorption technology. Moscow, Russia: Khimiya.

Kritenko, M. I., Tarantsev, A. A. and Shchebarov, Yu. G. (1995). Assessment of the significance of factors during their complex effect on the system. Bulletin of the Russian Academy of Sciences. Automation and telemechanics, 10, 35-43. 
Nalimov, V. V. and Chernova, N. A. (1965). Statistical methods for planning extreme experiments: textbook. Manual for universities. Moscow, Russia: Nauka.

Tarantsev, A. A., Ivakhnyuk, G. K., Pyatin, D. V. and Ivanov, A.V. (2016). Multivariate regression model of soil detoxification processes in emergency situations at oil and gas facilities. Problems of risk management in the technosphere, 40(4), 34-42.

Wentzel, E. S. (1998). Probability Theory: Textbook. Manual for universities. Moscow, Russia: Vysshaya shkola. 